\title{
Evaluation of syndromic surveillance in the \\ Netherlands: its added value and recommendations for implementation
}

C C van den Wijngaard (Kees.van.den.Wijngaard@rivm.nl) ${ }^{1}$, W van Pelt ${ }^{1}$, N J Nagelkerke ${ }^{2}$, M Kretzschmar ${ }^{1}$, M P Koopmans ${ }^{1,3}$

1. Rijksinstituut voor Volksgezondheid en Milieu (National Institute for Public Health and the Environment, RIVM), Bilthoven, the Netherlands

2. United Arab Emirates University, Al-Ain, United Arab Emirates

3. Erasmus Medical Center, Rotterdam, the Netherlands

Citation style for this article:

van den Wijngaard CC, van Pelt W, Nagelkerke NJ, Kretzschmar M, Koopmans MP. Evaluation of syndromic surveillance in the Netherlands: its added value and recommendations for implementation. Euro Surveill. 2011;16(9):pii=19806. Available online: http://www.eurosurveillance.org/ViewArticle.aspx?Articleld=19806

Article published on 3 March 2011

In the last decade, syndromic surveillance has increasingly been used worldwide for detecting increases or outbreaks of infectious diseases that might be missed by surveillance based on laboratory diagnoses and notifications by clinicians alone. There is, however, an ongoing debate about the feasibility of syndromic surveillance and its potential added value. Here we present our perspective on syndromic surveillance, based on the results of a retrospective analysis of syndromic data from six Dutch healthcare registries, covering 1999-2009 or part of this period. These registries had been designed for other purposes, but were evaluated for their potential use in signalling infectious disease dynamics and outbreaks. Our results show that syndromic surveillance clearly has added value in revealing the blind spots of traditional surveillance, in particular by detecting unusual, local outbreaks independently of diagnoses of specific pathogens, and by monitoring disease burden and virulence shifts of common pathogens. Therefore we recommend the use of syndromic surveillance for these applications.

\section{Background}

In the last decade, syndromic surveillance has increasingly been implemented to detect and monitor infectious disease outbreaks, as early detection and control may well mitigate the impact of epidemics [1-3]. In the United Kingdom, for example, a telephone health helpline (NHS Direct) is used for syndromic surveillance [1]; in France, a syndromic surveillance system based on hospital emergency data has been deployed [4]; and in North America several syndromic surveillance systems exist using data such as telephone helpline calls [5] and hospital emergency department visits $[2,6]$. Traditional outbreak detection based on astute clinicians and laboratory diagnoses can have blind spots for emerging diseases, because patients reporting with common symptoms (e.g. pneumonia) associated with the disease may not alarm clinicians, and uncommon or new pathogens can remain undetected by laboratories (such as initially happened in the outbreak of severe acute respiratory syndrome (SARS) in 2003). Syndromic surveillance may reveal such blind spots of traditional surveillance by monitoring elevations of common symptoms or clinical diagnoses such as shortness of breath or pneumonia.

The increasing use of syndromic surveillance seems driven by two factors: (i) high-profile disease events (e.g. the 2001 anthrax attacks, 2003 SARS outbreak, the threat of a new influenza pandemic, excess mortality due to heat waves) stressing the need for improved early warning surveillance; and (ii) the increased availability of electronic healthcare data, making largescale monitoring of non-specific health indicators increasingly feasible.

There is, however, an ongoing debate about the added value of syndromic surveillance. Some scepticism exists about the potential workload it may generate if used for real-time outbreak detection (i.e. if the system creates many false-positive signals) [7]. In the Netherlands, this debate has led to a research project to evaluate the potential value of syndromic surveillance for infectious disease surveillance and control, and to make recommendations for its implementation. The questions addressed were: (i) what syndromic data types track known dynamics of infectious diseases in the general population, and thus will also be likely to reflect emerging pathogen activity? (ii) can syndromic surveillance improve the monitoring of disease burden and/or detect shifts in the virulence of common pathogens? (iii) can syndromic surveillance detect local outbreaks that have a limited number of signals in time, independent of laboratory detection of the causative pathogens?

We addressed these questions by retrospectively analysing syndromic data from six Dutch healthcare registries, and also by ad hoc use of syndromic surveillance for upcoming infectious disease problems. To select 


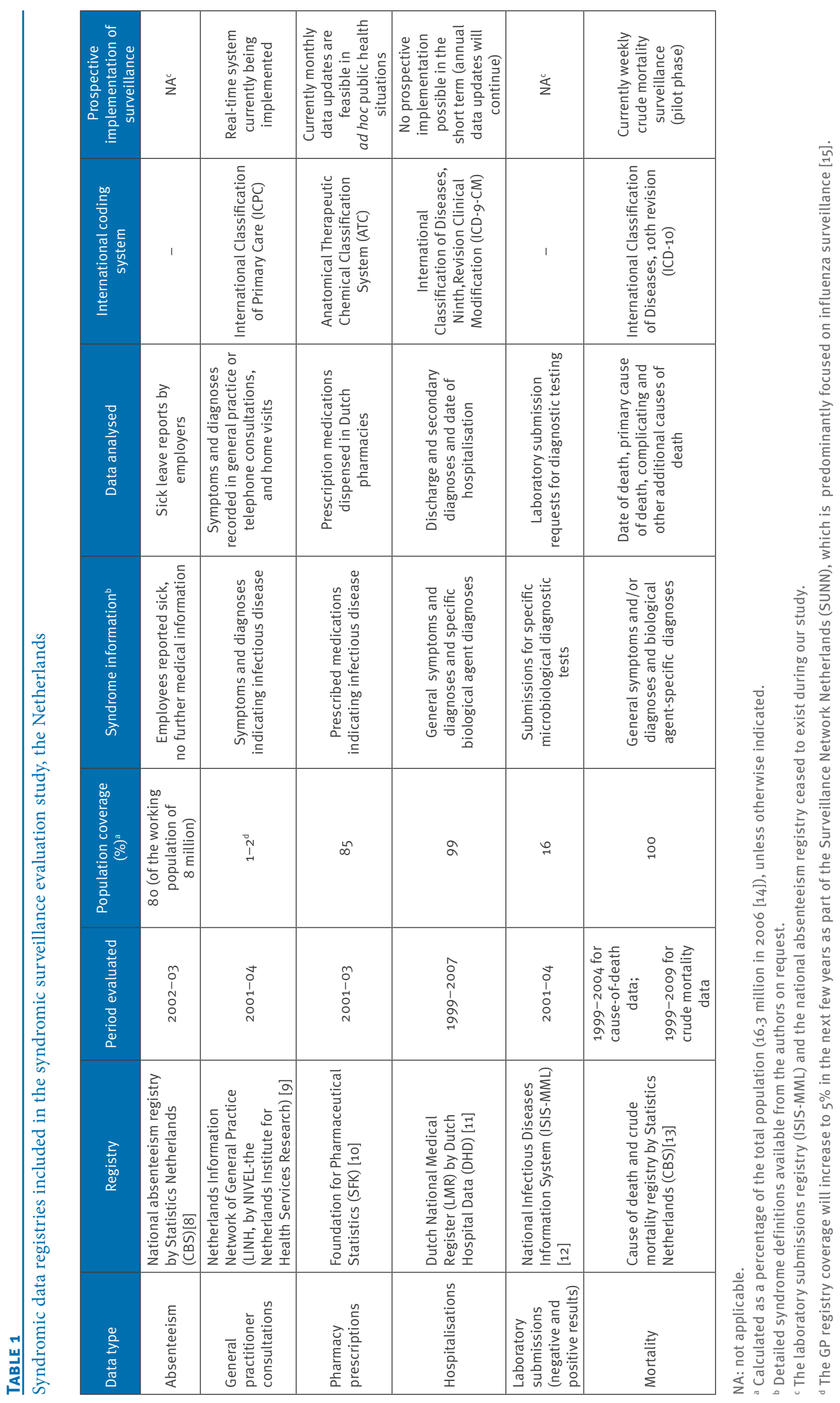




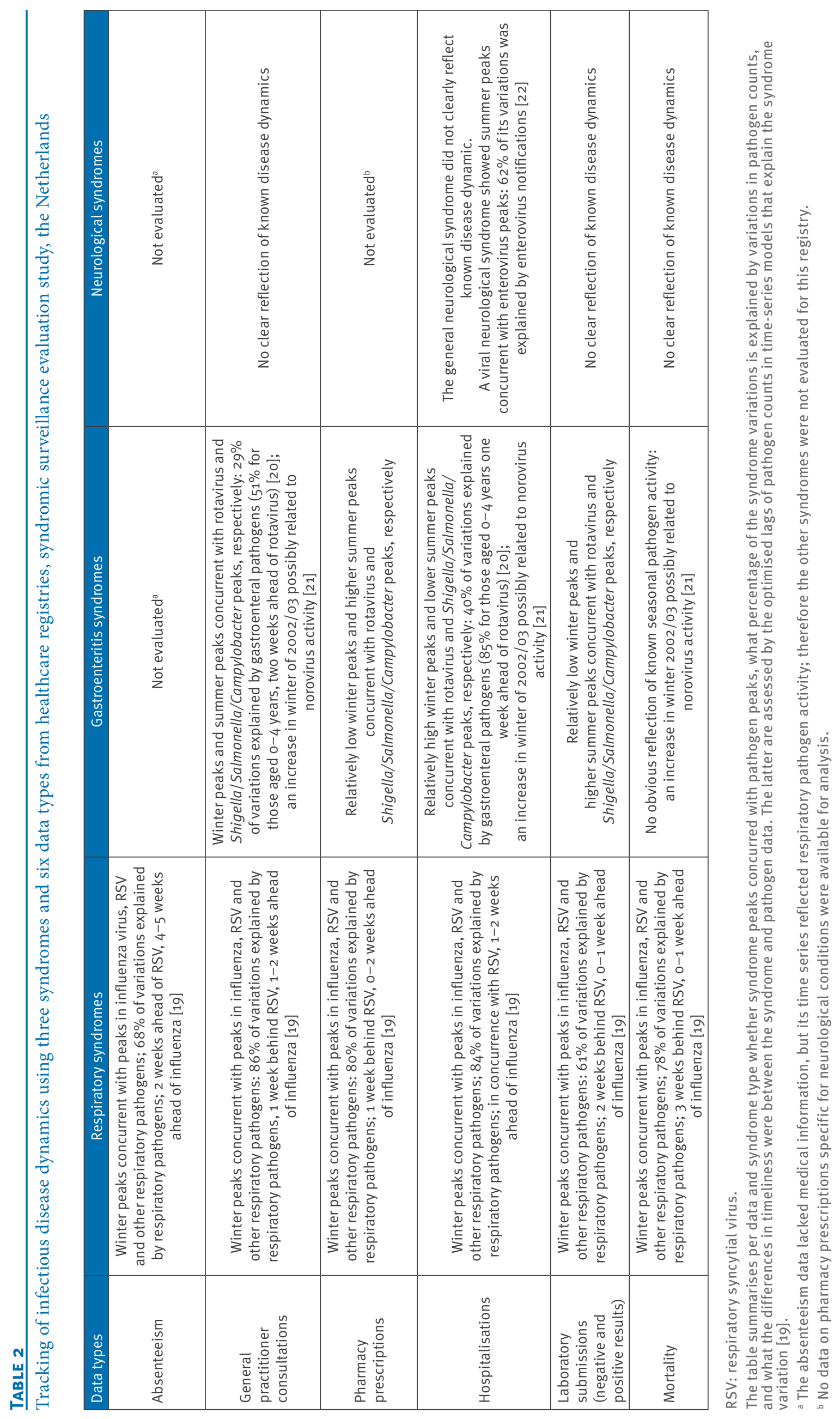


potential syndromic data sources, we asked Dutch healthcare registry owners to provide information on predefined criteria (coverage, timeliness of data entry and potential for transition to real-time data availability). Table 1 shows the registries included in the study, with data on work absenteeism, general practitioner (GP) consultations, pharmacy prescriptions, laboratory submissions, hospitalisations and mortality. Data were available for 1999-2009 or part of this period.

On the basis of available literature cited in PubMed on bioterrorism and natural infectious disease threats, we selected syndromes that were expected to reflect the clinical presentations of both high-threat (i.e. capable of causing major outbreaks of severe illness) and common pathogens $[16,17]$. This not only makes it possible to use common pathogen activity as a test case for these syndromes, but also implies that emergence of the high-threat pathogens concerned will be relatively difficult to recognise by clinicians. We selected respiratory syndromes (e.g. for high-threat pathogens such as Bacillus anthracis or a new pandemic influenza variant), gastroenteritis syndromes (e.g. caused by Vibrio cholerae infection) and neurological syndromes (e.g. caused by West Nile virus infection). The syndromes were defined for each registry, guided by a list of syndrome definitions defined by the United States Centers for Disease Control and Prevention [18] and experts in infectious diseases and medical microbiology at the Rijksinstituut voor Volksgezondheid en Milieu (National Institute for Public Health and the Environment, RIVM). The syndromes were then evaluated per registry for their potential use in signalling infectious disease dynamics and outbreaks.

In this article, we present our perspective on the added value of syndromic surveillance for infectious disease surveillance and control, based on the results of our evaluation study and in light of the literature up to and including 2010.

\section{Main findings of syndromic surveillance evaluation \\ Tracking infectious disease dynamics \\ in the general population}

The first question we addressed was to what extent trends in respiratory, gastroenteritis and neurological syndromes in the various registries reflect known pathogen activity, as measured by counts of detected pathogens (available from routine laboratory surveillance). This indicates whether these registries have the potential to reflect emerging pathogen activity (Table 2).

Of the three syndromes, respiratory syndromes were most closely associated with laboratory pathogen counts (Table 2), displaying higher levels in winter, which corresponded to higher counts of respiratory pathogens [19]. Up to $86 \%$ of the weekly syndrome variations (i.e. variance) in time were explained by weekly variations in respiratory pathogen counts, particularly of influenza viruses and respiratory syncytial virus (RSV), which is in line with other studies [23,24]. However, the respiratory syndromes in our study were zero to five weeks ahead of laboratory counts of influenza viruses, suggesting better timeliness of these syndromes. For RSV, the pathogen counts were concurrent with respiratory syndromes from hospitalisation registry data, which would be expected as most RSV tests are performed on hospitalised young children $[25,26]$. Most respiratory syndromes from other registry data lagged behind the RSV counts, which suggests that young children are affected relatively early in the annual RSV season.

The gastroenteritis syndromes showed winter peaks concurrent with increased rotavirus activity, and summer peaks concurrent with peaks in Shigella, Campylobacter and Salmonella activity (Table 2). Variation in the reporting of gastroenteritis syndromes explained by pathogen counts was lower (29-40\%) than in the respiratory syndromes, although it increased up to $85 \%$ when limiting the analysis to young children, with the syndromes' counts one to two weeks ahead of the laboratory rotavirus counts [20].

The reported general neurological syndromes did not clearly reflect known patterns of pathogen activity (Table 2). However, a more specific viral neurological syndrome - unexplained viral meningitis syndrome in the hospitalisation registry data did: $62 \%$ of the variation in the reporting of this syndrome was explained by known seasonal enterovirus activity, suggesting that elevated levels of unexplained viral meningitis indicate undiagnosed enterovirus infections [22].

The general practitioner consultations, pharmacy prescriptions, hospitalisations and mortality registry data thus showed good performance in timely tracking of respiratory and/or gastrointestinal disease, and the hospital registry data also showed moderate performance for neurological disease (Table 2). The advantage of using these four complementary registries together would be that they cover mild to very severe morbidity. The absenteeism registry data seemed most timely (ahead of laboratory surveillance data), but showed only moderate performance in tracking respiratory disease. This could be due to the fact that medical information is not available in this registry, and thus the data are a mix of all kinds of disease, although respiratory disease is clearly reflected in the time-series pattern. The laboratory submissions registry data showed, at most, a moderate performance for the three syndromes evaluated.

\section{Monitoring disease burden and detecting virulence shifts}

The second research question we addressed was whether syndromic surveillance improves the monitoring of disease burden and detects shifts in the virulence of common pathogens. We evaluated this by relating time series of syndromic surveillance data with 
pathogen-specific surveillance data to quantify the disease burden due to common pathogens over time. We found a clear association over time of norovirus laboratory surveillance data with mild-to-severe morbidity and even deaths in elderly people, observed in recent years, coinciding with emergence of new norovirus variants [21]. The emergence of these variants had been suspected but could not be assessed by any other routine surveillance system. In addition, for influenza we detected previously unknown shifts in the annual numbers of hospitalisations and deaths related to the number of influenza-like illness (ILI) cases, coinciding with shifts in the antigenicity of circulating viruses [27]. Such analyses can also be used for investigating the severity of pandemic influenza $A\left(\mathrm{H}_{1} \mathrm{~N}_{1}\right) 2009$ infection compared with that of seasonal influenza [28].

\section{Detecting local outbreaks}

The third question we addressed was whether syndromic surveillance can detect unexpected disease outbreaks in a timely manner. For this purpose, analysis of aggregated nationwide data may not be very sensitive: the large volume of the data (e.g. tens of thousands of respiratory syndrome hospitalisations per year) makes it impossible to detect outbreaks when they are still small. Local detection of syndrome elevations using a space-time algorithm might signal emerging outbreaks much sooner [29]. To test this, we used known outbreaks of Legionnaires' disease as positive controls of realistic severe respiratory disease outbreaks due to uncommon or new pathogens that may not be detected by traditional surveillance in a timely manner. Simulating prospective surveillance, we were able to timely detect these known outbreaks in syndromic hospital data using space-time scan statistics [29]. The fact that the overall alarm rate was modest (a mean of five local clusters detected per year) suggests that syndromic surveillance of hospitalisation data for respiratory disease can indeed be a useful early-warning tool for local outbreak detection. Using the same approach, previously unknown disease clusters plausibly due to Q fever were detected [30], thus illustrating that on some occasions syndromic surveillance can identify outbreaks that otherwise would remain undetected. These analyses were motivated by the clinical detection of a large Q fever outbreak in 2007 and the subsequent years, which raised the question whether smaller outbreaks might have preceded the 2007 outbreak. Real-time detection and investigation of these previously unknown clusters could possibly have led to earlier awareness of increased Q fever activity.

\section{Assessing the absence or limited}

\section{size of unusual disease events}

In public health practice, besides timely detection of unusual outbreaks, being able to assess and communicate the absence or limited size of unusual disease events can also be important. For example, Blendon et al. suggested that better communication to the public during the 2003 SARS outbreak might have prevented economic loss due to unnecessary precautions taken by the public (e.g. many people stayed away from crowded places, even in areas with a relatively low level of spread of the virus) [31]. Also during highprofile public events (e.g. the Olympics or G8 summits) $[32,33]$, syndromic surveillance will mainly confirm the absence of major, unusual disease outbreaks, since such outbreaks are rare events.

We also examined the value of syndromic data in assessing the absence or limited size of unusual disease triggered by specific public health concerns. For West Nile virus (WNV) infection, enhanced surveillance was established in the Netherlands by laboratory testing of cerebrospinal fluid (CSF) from patients with unexplained viral meningitis/encephalitis [22]. None of the CSFs collected in 2002 to 2004 tested positive for WNV, but the probability that WNV was indeed absent in the country could only be assessed from the annual count of unexplained viral meningitis/ encephalitis cases (as a denominator in relation to the number of CSF samples tested). For hepatitis $E$ and Ljungan virus infections, we inspected time series of unexplained hepatitis and abortion/perinatal death, respectively, and found no signs of emerging activity of these viruses. Rumours about a continuing increase of impetigo in children were countered by inspection of a time series of GP consultations for the infection.

\section{Other spin-offs of syndromic surveillance}

In addition to the above described applications, other uses of syndromic surveillance were illustrated during the 2009 influenza $A\left(\mathrm{H}_{1} \mathrm{~N}_{1}\right)$ pandemic. We used respiratory syndromic data on hospitalisations and GP consultations to plan the diagnostic capacity that would be needed if a larger proportion of the persons with respiratory symptoms would be tested - as is the case in the early stages of a pandemic [34]. Also early in the pandemic, the reaction of the public to media reports on pandemic influenza was illustrated by sharp elevations in the number of oseltamivir prescriptions [35]. This information was used to urge physicians to exercise restraint in prescribing oseltamivir, in order to decrease the risk of oseltamivir shortage and viral resistance later in the pandemic.

\section{Data requirements}

The results of our project suggest specific data requirements for successful syndromic surveillance. Data quality is important for all applications of syndromic surveillance, but probably mostly for local outbreak detection. Here, relatively small artefacts - for example, duplicate details of the same patient in one registry - can result in false alarms, as we experienced when using hospital data for space-time cluster detection $[29,30]$. In a real-time setting (e.g. daily or weekly data updates), reporting delays can also lead to data artefacts and false alarms, if, for example, there is a delay in hospitals submitting their data [36]. In addition to having few data artefacts, data need to be representative, and for local outbreak detection, they also need to have a high coverage (preferably close 
to $100 \%$ ) to be able to timely detect local outbreaks in any region. By using data with relatively low coverage levels, sensitivity for local outbreaks obviously will be reduced $[37,38]$. Nordin et al. used simulated anthrax attack data, and integrated the simulated data into actual physicians' visit data to show that the sensitivity for detecting respiratory outbreaks resulting from bioterrorism was not very high [37]. However, the authors evaluated a maximum system coverage of only $36 \%$ of the population. In another study, Balter et al. reported that a syndromic surveillance system in New York City sometimes missed several gastroenteritis outbreaks due to data quality (e.g. miscoding of patients' chief complaints) and coverage problems (e.g. some hospitals did not participate in the system) [38].

For effective signal verification, sufficient information on individual patients' characteristics and concurrent laboratory trends has to be available to identify possible causes of generated signals. For example, we interpreted local respiratory syndrome clusters in relation to local influenza or RSV activity: if the age distribution of cases reflected the usual pattern for these viruses, we regarded further investigation unnecessary [29]. Also, the rise in oseltamivir prescriptions early in the 2009 influenza $A\left(\mathrm{H}_{1} \mathrm{~N}_{1}\right)$ pandemic could be ascribed to the 'worried well', because laboratory surveillance showed that influenza virus activity had not increased [35]. Without such verification options, the value of syndromic surveillance is limited [38].

\section{Cost-effectiveness of real-time}

\section{surveillance systems}

An important question is whether syndromic surveillance is cost effective. Events such as a bioterrorist attack, a SARS epidemic or an influenza pandemic are rare and the question arises how much of the public health budget should be spent on a detection system for such rare events.

The costs of a surveillance system can be easily estimated. Studies that report the operating costs associated with real-time syndromic surveillance found annual operating costs ranging from US\$ 130,000150,000 to US\$280,000 [39]. However, estimating its benefits is less obvious. Kaufmann et al. reported that the economic damage caused by a bioterrorist attack can amount to millions or even billions of dollars [40]. The SARS epidemic in 2003 and the influenza pandemic in 2009 showed that the economic damage caused by naturally occurring outbreaks can be similarly high [41,42]. If similar disease events emerge every few years, and syndromic surveillance leads to earlier detection and control of such outbreaks, then the benefits of syndromic surveillance are likely to outweigh its costs. The question here is whether earlier detection would indeed lead to control or at least reduced impact of a new disease, for instance, SARS or influenza $A\left(\mathrm{H}_{1} \mathrm{~N}_{1}\right)_{2009}$ infection. Simulation studies could help to further evaluate which specific types of major disease events syndromic surveillance could probably lead to interventions that limit the economic damage.

Possibly just as important as the benefits arising from earlier detection and control is the downscaling of unnecessary interventions during ongoing outbreaks. This requires quick assessment of the limited size and severity of outbreaks. For example, if the severity of a new pandemic can be quickly assessed - as the World Health Organization (WHO) requires [43] - by reliable syndromic hospital surveillance of severe respiratory infections, costly interventions such as quarantine and prophylactic treatment or vaccination could be downscaled or stopped earlier if the disease is only mild.

In the Netherlands, prospective surveillance has now started for crude mortality data, with weekly data collection and analysis since the 2009 influenza pandemic. The existing mortality registry allows prospective implementation at relatively low extra cost. Real-time data collection is currently also being implemented for the Dutch GP registry (Table 1). Including hospital data and other data types in future syndromic surveillance systems may also be feasible at limited cost, if the data collection can be integrated into already planned real-time, future data infrastructures such as the Dutch national health-information-exchange system [44].

\section{Recommendations}

On the basis of our evaluation, we recommend the use of syndromic surveillance to reveal blind spots of traditional surveillance, in particular by detecting unusual, local outbreaks independently of laboratory diagnoses of specific pathogens, and by monitoring disease burden and virulence shifts of common pathogens.

Our results are mostly based on retrospective analysis of syndromic data of high quality and coverage. If prospective collection of such syndromic data is not feasible, real-time early warning for local outbreaks should not be performed, since true outbreaks will probably be missed while at the same time numerous false alarms will be generated. For real-time early warning, sufficient laboratory and epidemiological information is needed, in order to be able to quickly verify possible causes of syndromic signals, and thus recognise relevant signals that might need a response. Retrospective analyses as performed in our evaluation can validate the relevant data and analyses before prospective implementation of a syndromic surveillance system.

\section{Acknowledgements}

We thank Statistics Netherlands (CBS), the Dutch Foundation for Pharmaceutical Statistics (SFK), ISIS-labs, Dutch Hospital Data and Prismant (LMR), Netherlands Institute for Health Services Research (NIVEL) (regarding both the Netherlands Information Network of General Practice (LINH) and the Continuous Morbidity Registration (CMR) sentinel stations) for providing data, and the members of the Dutch Working Group on Clinical Virology, for providing access to the registry on weekly positive diagnostic results. 
1. Cooper DL, Verlander NQ, Smith GE, Charlett A, Gerard E, Willocks L, et al. Can syndromic surveillance data detect local outbreaks of communicable disease? A model using a historical cryptosporidiosis outbreak. Epidemiol Infect. 2006;134(1):13-20.

2. Heffernan R, Mostashari F, Das D, Karpati A, Kuldorff M, Weiss D. Syndromic surveillance in public health practice, New York City. Emerg Infect Dis. 2004;10(5):858-64.

3. Bellika JG, Hasvold T, Hartvigsen G. Propagation of program control: a tool for distributed disease surveillance. Int J Med Inform. 2007;76(4):313-29.

4. Josseran L, Fouillet A, Caillère N, Brun-Ney D, llef D, Brucker G, et al. Assessment of a syndromic surveillance system based on morbidity data: results from the Oscour network during a heat wave. PLoS One. 2010;5(8):e11984.

5. Caudle JM, van Dijk A, Rolland E, Moore KM. Telehealth Ontario detection of gastrointestinal illness outbreaks. Can J Public Health. 2009;100(4):253-7.

6. van-Dijk A, Aramini J, Edge G, Moore KM. Real-time surveillance for respiratory disease outbreaks, Ontario, Canada. Emerg Infect Dis. 2009;15(5):799-801.

7. Hope K, Durrheim DN, d'Espaignet ET, Dalton C. Syndromic Surveillance: is it a useful tool for local outbreak detection? J Epidemiol Community Health. 2006;60(5):374-5.

8. Statistics Netherlands (CBS). Ziekteverzuim volgens de Nationale Verzuimstatistiek (tot 2006) [Absenteeism according to National Absenteeism Registry (until 2006)]. The Hague: CBS. [Accessed 1 Mar 2011]. Dutch. Available from: http://www. cbs.nl/nl-NL/menu/methoden/dataverzameling/ziekteverzuimvolgens-de-nationale-verzuimstatistiek.htm

9. The Netherlands Institute for Health Services Research (NIVEL). LINH: Landelijk informatienetwerk huisartsenzorg [LINH: the Netherlands Information Network of General Practice]. Utrecht: NIVEL. [Accessed 28 Feb 2011]. Dutch. Available from: http:// www.nivel.nl/linh/

10. Stichting Farmaceutische Kengetallen (SFK). Foundation for pharmaceutical statistics. The Hague: SFK. [Accessed 28 Feb 2011]. Available from: http://www.sfk.nl/algemeen/english. html

11. Dutch Hospital Data (DHD). Landelijke Medische Registratie (LMR) [Dutch National Medical Register]. Utrecht: DHD. [Accessed 28 Feb 2011]. Available from: http://www.dutchhospitaldata.nl/Registraties/LMR. php?zoom_highlight=LMR

12. Rijksinstituut voor Volksgezondheid en Milieu (National Institute for Public Health and the Environment, RIVM). Evaluatie van ISIS-MML [Evaluation of the Netherlands Infectious Diseases Surveillance Information System]. Bilthoven: RIVM. [Accessed 28 Feb 2011]. Dutch. Available from: http://www.rivm.nl/bibliotheek/rapporten/210211001. html

13. Statistics Netherlands (CBS). Doodsoorzakenstatistiek [Death cause statistics]. The Hague: CBS. [Accessed 1 Mar 2011]. Dutch. Available from: http://www.cbs.nl/nl-NL/menu/ methoden/dataverzameling/doodsoorzakenstatistiek.htm

14. Statistics Netherlands (CBS). Bevolking per maand; leeftijd, geslacht, herkomst, generatie [Population by month; age, sex, origin of immigrants, generation]. The Hague: CBS. [Accessed 28 Feb 2011]. Dutch. Available from: http://statline.cbs.nl/ StatWeb/publication/?VW=T\&DM=SLNL\&PA=7109oned

15. The Netherlands Institute for Health Services Research (NIVEL). SuNN: Surveillance Netwerk Nederland [SuNN: Surveillance Network Netherlands]. Utrecht: NIVEL. [Accessed 28 Feb 2011]. Dutch. Available from: http://www.nivel.nl/sunn

16. Rotz LD, Khan AS, Lillibridge SR, Ostroff SM, Hughes JM. Public health assessment of potential biological terrorism agents. Emerg Infect Dis. 2002;8(2):225-30.

17. Wagner MM, Dato V, Dowling JN, Allswede M. Representative threats for research in public health surveillance. J Biomed Inform. 2003;36(3):177-88.

18. Centers for Disease Control and Prevention (CDC). Syndrome definitions for diseases associated with critical bioterrorismassociated agents. Atlanta: CDC; 2003. Available from: http://www.bt.cdc.gov/surveillance/syndromedef/word/ syndromedefinitions.doc

19. van den Wijngaard C, van Asten L, van Pelt W, Nagelkerke NJ, Verheij R, de Neeling AJ, et al. Validation of syndromic surveillance for respiratory pathogen activity. Emerg Infect Dis. 2008;14(6):917-25.

20. van Asten L, van den Wijngaard C, van Pelt W, van Vliet $H$, Koopmans M. Understanding the dynamics of gastro-intestinal syndrome: general practioner and hospital data vs laboratory surveillance. Advances in Disease Surveillance, 2007;2:215 Available from: http://www.isdsjournal.org/articles/949.pdf

21. van Asten L, van den Wijngaard C, Siebenga J, van Pelt W, van Vliet H, Koopmans M. Greater pathogenicity of norovirus strains in 2003? A syndromic approach. Advances in Disease Surveillance $2007 ; 2: 175$. Available from: http://isdsjournal. org//articles/2825.pdf.

22. Rockx B, van Asten L, van den Wijngaard C, Godeke GJ, Goehring L, Vennema $H$, et al. Syndromic surveillance in the Netherlands for the early detection of West Nile virus epidemics. Vector Borne Zoonotic Dis. 2006;6(2):161-9.

23. Bourgeois FT, Olson KL, Brownstein JS, McAdam AJ, MandI KD. Validation of syndromic surveillance for respiratory infections. Ann Emerg Med. 2006;47(3):265.e1.

24. Cooper DL, Smith GE, Edmunds WJ, Joseph C, Gerard E, George RC. The contribution of respiratory pathogens to the seasonality of NHS Direct calls. J Infect. 2007;55(3):240-8.

25. Terletskaia-Ladwig E, Enders G, Schalasta G, Enders M. Defining the timing of respiratory syncytial virus (RSV) outbreaks: an epidemiological study. BMC Infect Dis. 2005;5(1):20.

26. Simoes EA. Respiratory syncytial virus infection. Lancet. 1999;354(9181):847-52.

27. van den Wijngaard CC, van Asten L, Meijer A, van Pelt W, Nagelkerke NJ, Donker GA, et al. Detection of excess influenza severity: associating respiratory hospitalization and mortality data with reports of influenza-like illness by primary care physicians. Am J Public Health. 2010;100(11):2248-54.

28. van 't Klooster TM, Wielders CC, Donker T, Isken L, Meijer A, van den Wijngaard CC, et al. Surveillance of hospitalisations for 2009 pandemic influenza $\mathrm{A}\left(\mathrm{H}_{1} \mathrm{~N}_{1}\right)$ in the Netherlands, 5 June - 31 December 2009. Euro Surveill. 2010;15(2). pii: 19461. Available from: http://www.eurosurveillance.org/ViewArticle. aspx?Articleld $=19461$

29. van den Wijngaard CC, van Asten L, van Pelt W, Doornbos G, Nagelkerke NJ, Donker GA, et al. Syndromic surveillance for local outbreaks of lower-respiratory infections: would it work? PLoS One. 2010;5(4):e10406.

30. van den Wijngaard CC, Dijkstra F, van Pelt W, van Asten L, Kretzschmar M, Schimmer B, et al. In search of hidden Q-fever outbreaks: linking syndromic hospital clusters to infected goat farms. Epidemiol Infect. 2011;139(1):19-26.

31. Blendon RJ, Benson JM, DesRoches CM, Raleigh E, TaylorClark K. The public's response to severe acute respiratory syndrome in Toronto and the United States. Clin Infect Dis. 2004;38(7):925-31.

32. Gesteland PH, Gardner RM, Tsui FC, Espino JU, Rolfs RT, James $\mathrm{BC}$, et al. Automated syndromic surveillance for the 2002 Winter Olympics. J Am Med Inform Assoc. 2003;10(6):547-54.

33. Meyer N, McMenamin J, Robertson C, Donaghy M, Allardice G, Cooper D. A multi-data source surveillance system to detect a bioterrorism attack during the G8 Summit in Scotland. Epidemiol Infect. 2008;136(7):876-85.

34. van Asten $L$, van der Lubben $M$, van den Wijngaard C, van Pelt W, Verheij R, Jacobi A, et al. Strengthening the diagnostic capacity to detect Bio Safety Level 3 organisms in unusual respiratory viral outbreaks. J Clin Virol. 2009;45(3):185-90.

35. van den Wijngaard CC, van Steenbergen JE, van der Sande MA, Koopmans MP. [New influenza A ( $\left.\mathrm{H}_{1} \mathrm{~N}_{1}\right)$ : advised indication and prescription of antiviral drugs]. Ned Tijdschr Geneeskd. 2009;153:A1053. Dutch.

36. Travers D, Barnett C, Ising A, Waller A. Timeliness of emergency department diagnoses for syndromic surveillance. AMIA Annu Symp Proc 2006;769-73.

37. Nordin JD, Goodman MJ, Kulldorff M, Ritzwoller DP, Abrams $A M$, Kleinman K, et al. Simulated anthrax attacks and syndromic surveillance. Emerg Infect Dis. 2005;11(9):1394-8.

38. Balter S, Weiss D, Hanson H, Reddy V, Das D, Heffernan R. Three years of emergency department gastrointestinal syndromic surveillance in New York City: what have we found? MMWR Morb Mortal Wkly Rep. 2005;54 Suppl:175-80.

39. Kirkwood A, Guenther E, Fleischauer AT, Gunn J, Hutwagner L, Barry MA. Direct cost associated with the development and implementation of a local syndromic surveillance system. I Public Health Manag Pract. 2007;13(2):194-9.

40. Kaufmann AF, Meltzer MI, Schmid GP. The economic impact of a bioterrorist attack: are prevention and postattack intervention programs justifiable? Emerg Infect Dis. 1997;3(2):83-94.

41. Dan YY, Tambyah PA, Sim J, Lim J, Hsu LY, Chow WL, et al. Costeffectiveness analysis of hospital infection control response to an epidemic respiratory virus threat. Emerg Infect Dis. 2009;15(12):1909-16. 
42. Brouwers L, Cakici B, Camitz M, Tegnell A, Boman M. Economic consequences to society of pandemic $\mathrm{H}_{1} \mathrm{~N}_{1}$ influenza 2009 -

preliminary results for Sweden. Euro Surveill. 2009;14(37).

pii: 19333. Available from: http://www.eurosurveillance.org/

ViewArticle.aspx?Articleld $=19333$

43. World Health Organization (WHO). Pandemic influenza

preparedness and response: a WHO guidance document.

Geneva: WHO: 2009. Available from: http://www.who.int/csr/ disease/influenza/PIPGuidanceo9.pdf

44. National Government of the Netherlands. Elektronisch patiëntendossier. [Patient electronic medical record]. The

Hague: National Government of The Netherlands [Accessed 28 Feb 2011]. Dutch. Available from: http://www.rijksoverheid.nl/ onderwerpen/elektronisch-patientendossier\#ref-minvws 